\title{
O MERCADO EDITORIAL CIENTÍFICO À LUZ dOS CONCEITOS ECONÔMICOS
}

Jackeline Ferreira da Encarnação'

\section{Resumo}

Esse trabalho tem por objetivo analisar a existência do mercado editorial científico e sua necessidade de internacionalização à luz dos conceitos econômicos, tendo em vista definições como assimetria de informação e falhas de mercado. A conclusão deste estudo, é que a intervenção governamental leva a produtividade científica, no entanto, não conduz a internacionalização.

Palavras chaves: Produção científica; Intervenção governamental; Internacionalização; Economia

Classificação JEL: O2; O29

\section{INTRODUÇÃO}

Atualmente o contexto da publicação científica brasileira é bastante promissor. De acordo com a Thompson Reuters, em 2007, o Brasil participava com 34 periódicos indexados correspondendo a 18\% de toda produção brasileira. Em 2009, esse número elevou-se a 129 periódicos indexados, correspondendo a $36 \%$ de toda produção científica brasileira. Com o crescimento eminente, o país sai da posição $17^{\mathrm{a}}$ para ocupar a $13^{\mathrm{a}}$ no ranking mundial da produção científica (PACKER, 2011), superando países como Holanda, Israel e Suíça (REGALARDO, 2010).

Mestre em Gestão Internacional de Negócios pela Escola Superior de Propaganda e Marketing - ESPM. Profissional do Mercado Editorial Científico, e-mail: jac@espm.br 
O crescimento mencionado deve-se em parte à política conduzida pela CAPES - Coordenação de Aperfeiçoamento de Pessoal de Nível Superior aos cursos de pós-graduação stricto-sensu. No portal da referida agência, informa que houve um aumento de $20 \%$ nos cursos de mestrado e doutorado, constatado na última avaliação trienal (2007-2010), sendo assim, com o acréscimo no número de cursos, cresce também a necessidade de publicação (SANDES-GUIMARÃES, 2013).

No entanto, o desafio da produção científica brasileira não consiste no volume de sua produção, e sim, em sua visibilidade internacional. Para Fiorin, quando se trata da prerrogativa produção científica "um dos critérios considerados mais relevantes é o grau de sua internacionalização. É a inserção global que indica a participação de um país na produção científica mundial" (FIORIN, 2007, p. 264). Tal contexto pode ser traduzido pelos principais indicadores de citação, tais como: JCR Journal Citation Reports e o H-scopus, além de indicadores de visibilidade, são considerados também como parâmetros de qualidade. Apesar de haver grande número de revistas indexadas em bases como a ISI - Institute of Scientific Information e Scopus, bases responsáveis por tais indicadores, o impacto da produção nacional é muito baixo (PACKER, 2011; ALISSON, 2012).

Face ao exposto, este trabalho tem o objetivo de analisar a existência do mercado editorial científico e sua necessidade de internacionalização à luz dos conceitos econômicos, tendo em vista definições como assimetria de informação e falhas de mercado. A análise de tais conceitos é uma forma de expandir a compreensão que acerca o ambiente econômico e aplicá-los a outros contextos.

A metodologia utilizada será basicamente a análise bibliográfica dos temas que serão abordados. O trabalho em questão além desta introdução será composto por mais três seções: A primeira será a apresentação da base teórica relativo aos conceitos econômicos, bem como aos periódicos científicos. A segunda seção será composta pela discussão do que foi apresentado e por fim a conclusão.

\section{REFERENCIAL TEÓRICO}

Schettino (2006) alega que a NEI - Nova Economia Institucional considera que uma instituição é um contrato. "As leis contratuais servem 
o propósito de capacitar as pessoas a fazer acordos com compromissos que de outra forma não mereceriam crédito" (SCHETTINO, 2006, p. 25 apud ELSTER, 1989 p. 176). Sendo assim, o modelo Agente-Principal é a referência na literatura econômica para estudar as relações contratuais.
O Principal é o responsável pelo desenho do contrato que será oferecido ao Agente
O Agente aceita o contrato apenas se desejar, caso o contrato lhe traga um ganho de utilidade maior que outra opção.
O Agente exerce um esforço para cumprimento do contrato. (REIS, 2012, p. 13).

Os problemas de assimetria de informações surgem justamente da relação entre principal e agente.

\subsection{Assimetria de Informação}

Em qualquer transação financeira ou comercial torna-se essencial o conhecimento e a informação em relação ao que esta sendo negociado, de forma que todos os agentes envolvidos sejam contemplados. Para Lima (2006) "Conhecimento e informação são elementos decisivos em todos os processos da cadeia produtiva, visto que o processo sempre está baseado em algum grau de conhecimento e no processo de informação" (LIMA, 2006, p. 132). Sua ampla circulação faz com que aumente a probabilidade de sucesso dos agenciadores de forma que haja benefícios a todos ao longo do processo.

No entanto, a informação livre e sem barreiras encontra-se somente em modelos de mercados o qual os economistas a denominam de concorrência perfeita. Este modelo definido como estático e em constante equilíbrio, deve-se ao fato, de haver inúmeros vendedores ofertando o mesmo produto com as mesmas características e ao mesmo preço, sem nenhuma alteração no processo empresarial. (SOTO, 2013).

Para Anderson (2013), modelos econômicos em que não há falhas de mercados e que se obtêm informações necessárias a qualquer momento, são modelos irrealistas e não corresponde a realidade. Em modelos realistas, a informação esta associada à ideia da incerteza, esta por sua vez, inserido também na configuração do processo da cadeia produtiva. Schettino (2006) 
argumenta que, da mesma forma, a informação esta associada a questão do poder, uma vez que, consegue influenciar diretamente o processo decisório.

A linha teórica que estuda tal conjuntura no contexto econômico é denominada como assimetria de informação. A temática começou a ser pesquisada no início dos anos 70 pelos acadêmicos, George Arthur Akerlof (Universidade da Califórnia), Joseph Eugene Stiglitz (Universidade de Columbia) e Andrew Michael Spence (Universidade de Stanford), o qual resultou o Prêmio Nobel de economia em 2001 pelas as análises sobre "mercados com informações assimétricas" e pelos os estudos no "avanços na análise dos mercados e do controle de informação".

Assimetria de informação ocorre quando, em determinada transação econômica, uma das partes (agente) detém informações relevantes em relação à outra parte, ou seja, comprador e vendedor não dispõem da mesma informação. $\mathrm{O}$ vendedor de determinado produto frequentemente possui melhores informações a respeito da qualidade do produto que vende em relação ao comprador (PINDYCK, RUBINFELD, 2004). A falta de informações exatas e suficientes de forma que oriente os agentes econômicos a agir eficientemente é fonte do mau funcionamento de mercados que resulta em falhas de mercados e perdas do bem estar social (LIMA, 2006).

A ineficiência do mercado também é fruto de dois fatores que advém da assimetria de informação, entre essas, seleção adversa e risco moral. No entanto, para amenizar tal ineficiência, o produtor emite sinais ao mercado, disponibilizando informações, com a finalidade de comunicar o consumidor a respeito da qualidade dos seus produtos.

\subsection{Seleção Adversa}

A seleção adversa ocorre quando "produto de qualidades distintas são vendidos ao mesmo preço, porque comprados e vendedores não estão suficientemente informados para determinar a qualidade real do produto no momento da compra. Como resultado, muitos produtos de baixa qualidade e poucos de alta são vendidos no mercado". (PINDYCK, RUBINFELD, 2004, p. 604).

O tema em questão é bastante presente no mercado de seguros. Indivíduos propensos a altos riscos são os que mais demandam por serviços 
em seguro, seja este patrimonial, automotivo, saúde, ou qualquer outro. No entanto, a seguradora não aumenta o valor de forma que reflita os altos riscos em razão da informação assimétrica. O individuo que adquire o seguro tem mais informações a respeito de si próprias (saúde, atitudes e hábitos de risco) do que a seguradora. $\mathrm{O}$ fato dos indivíduos mais propensos ao risco ter uma maior demanda pelo seguro (seja ele qual for) faz com que este tipo de serviço aumente o seu valor, desestimulando assim as pessoas de baixo risco adquirir seguros. A seleção adversa acorre justamente nesta conjuntura, que é a seleção dos consumidores menos desejáveis.

Para lidar com esta situação as seguradoras desenvolveram métodos que envolvem a extração de informações apropriadas de modo que, por meio desses dados, a seguradora possa classificar os segurados em alto e baixo risco, assim podendo adequar os valores cobrados.

\subsection{Risco Moral}

Para Seabra (2009) o risco moral existe quando "uma parte apresenta ações que não são observadas e que podem afetar a probabilidade ou a magnitude de um pagamento ou a associado a um evento". Significa dizer que tal conceito esta associado a mudança de comportamento por parte do agente após assumir o compromisso relativo ao contrato.

No caso dos seguros, após assinatura do contrato, o agente deixa de tomar os devidos cuidados que o levarão a requerer os serviços da contratada, assim aumentando a probabilidade de roubos, faltando com os devidos cuidados com a saúde, etc. A seguradora está sujeita ao risco moral, a partir do momento que não consegue prever as ações do individuo que aumentem na probabilidade de eventos desfavoráveis.

A diferença entre a seleção adversa e risco moral reside basicamente no que permeia o contrato. A primeira consiste na "impossibilidade de se observar características relacionadas a pessoa antes que as partes se envolvam em uma relação contratual". O risco moral, "é a impossibilidade de observar as características após as partes entrarem em uma relação contratual". (MANSFIELD, YOHE, 2006). 


\subsection{Sinalização de Mercado}

Mercados em que há assimetria de informações a presença de produtos com qualidade duvidosa é constante. Isto se deve ao fato dos vendedores possuírem mais informações em relação ao produto do que os compradores. Este por sua vez, deduz que o produto seja de baixa qualidade, ocasionando no mercado a diminuição do valor da mercadoria, e da mesma forma, a baixa demanda por ele. Este ciclo, logo, ocasiona a ineficiência do mercado.

Uma das formas que o mercado busca para resolver a assimetria de informação é a sinalização do mercado, definida como "um processo pelo qual os vendedores enviam sinais aos compradores, transmitindo informações a respeito da qualidade do produto". (PINDYCK, RUBINFELD, 2004, p. 608). A forma de emiti-los, que pode ser por meio de garantias e certificados, é um sinal importante para o consumidor. $\mathrm{O}$ fabricante ao emitir tais documentos, sinaliza para o comprador que o seu produto tem qualidade. Caso contrário, se emitir a garantia de qualidade e o produto não corresponder a essas características, o empresário facilmente perderá dinheiro e credibilidade.

A sinalização de mercado não fica restrita somente a troca de bens, é possível também presenciá-la também em outros tipos de mercado, como por exemplo, o mercado de trabalho. Neste, o sinal que é mais valorizado pelas organizações é a formação educacional, pois, tem-se em vista que, os indivíduos com melhor formação poderão contribuir acentuadamente por meio de sua produtividade, do que aqueles com baixa formação educacional. Para Pindyck, Rubinfeld (2004), mesmo que a educação não aprimore a produtividade de alguém, ainda sim é o melhor sinal, pessoas mais produtivas tendem a buscar níveis mais elevados de educação.

\subsection{Falhas de Mercado}

Conforme mencionado anteriormente, a assimetria de informação conduz a falhas de mercados, este por sua vez, gerando a ineficiência do mercado, ou seja, a economia produz resultados que não são efetivos. Outra forma de lidar com a assimetria de informação, além da sinalização de mercado, são as regulamentações realizadas pelo poder público, os quais 
definem as regras e condutas para as organizações e cidadãos. As atividades regulatórias podem ser realizadas por "leis, portarias, regulamentos formais e regras informais emanadas de todas as instâncias de governo e decisões tomadas por organismos não governamentais ou de auto-regulação para os quais o governo delega status regulatório" (COSTA, et al, 2001, p. 194). As intervenções governamentais têm como propósito melhorar o funcionamento do mercado, de forma que a ineficiência associado às perdas sejam minimizadas, e, questões relacionadas ao bem estar social, sejam maximizados (CAMPOS, 2008).

Para Omar (2001), as principais fontes que deixam de gerar resultado ideal no mercado são: bens públicos, monopólio natural; externalidades e assimetria de informação, descritos a seguir.

Bens Públicos - É um tipo de serviço que deve estar disponível tanto a um grupo pequeno de pessoas quanto a um grupo grande sem que seus custos sejam alterados. Pode-se citar como exemplo, sistema de defesa, justiça e segurança. São aracterizados também "pela impossibilidade da exclusão de qualquer pessoa de desfrutar os seus benefícios, uma vez que o bem tenha sido provido" (OMAR, 2001, p. 215, apud BAUMOL, 1965, p.521).

Outro atributo deste tipo de bem é a falta da previsão de lucros, tendo em vista que não se pode evitar que um indivíduo utilize estes serviços, bem como, obrigá-lo que efetue pagamentos por ter utilizado.

Monopólio Natural - São empresas que detém poder de monopólio. Por não haver competidores, essas empresas não são incentivadas a diminuir os custos de produção e investir em inovação tecnológica para melhorar o produto. Ao contrário, são organizações geram que na economia ineficiências cobrando valores acima do custo marginal (custo de produzir uma unidade adicional), ocasionando lucros extraordinários.

Externalidade - É uma atividade econômica exercida por uma organização ou pessoa que afeta outro individuo que não esta diretamente ligada à atividade, e podem ser de efeito positivo ou negativo.

A externalidade positiva Campos (2008) a associou ao beneficio social, pois, leva em consideração o impacto da atividade para todos que estão inseridos na sociedade. É o caso da educação, todos que tem acesso a este recurso, possibilita à sociedade uma força de trabalho capacitada e geração de crescimento econômico. 
A externalidade negativa Campos (2008) associou ao custo privado, significa dizer que, os custos da produção não estão internalizados, e, são repassados indevidamente para sociedade. Em particular, uma organização que almeja aumentar os seus lucros, arcará com as despesas que foram geradas, no entanto, a poluição que a empresa gerou afeta toda a sociedade, isto é um custo social, o qual a empresa não arca.

Assimetria de informação - tema explorado no inicio da seção.

\subsection{Editoração Científica}

No campo da editoração científica os termos, revistas acadêmicas, revistas científicas, periódicos científicos, são utilizadas com o mesmo objetivo, recurso que o pesquisador tem disponível para divulgação dos resultados de sua pesquisa.

Complementando a noção de quais seriam as funções do periódico científico, Miranda e Pereira (1996) informam que são "um conjunto de atividades associadas à produção, disseminação e uso da informação", além de associá-lo também a institucionalização do conhecimento. (MIRANDA, PEREIRA, 1996, p. 375). Para os autores Gruszynski e Sanseverino (2005), o vinculam a quatro funções básicas: comunicação formal dos resultados de pesquisa para comunidade acadêmica; preservação do conhecimento gerado; estabelecimento da propriedade intelectual e manutenção do padrão de qualidade da ciência. Da mesma forma, Sandes-Guimarães (2012) entende que a função de um periódico seja "registrar, disseminar e comunicar o conhecimento científico de qualidade e de interesse social. Com isso, permite-se estabelecer a prioridade das descobertas, indicar a evolução de uma ciência, além de servir como fonte de informação para inicio de novas pesquisas e trabalhos" (SANDES-GUIMARÃES, 2012, p. 30).

Apesar das pequenas anuncias entre as definições, o que se presencia é que o periódico científico cumpre o papel de principal veículo de comunicação e divulgação da pesquisa cientifica.

No Brasil o órgão que regulamenta o setor de publicação científica é a CAPES - Coordenação de Aperfeiçoamento de Pessoal de Nível Superior. Criado pelo Decreto n ${ }^{\circ} 29.741$ de 11 de julho de 1951, realizou suas atividades até a década de 90, quando o governo Collor determinou a extinção da 
CAPES. Por pressão da comunidade acadêmica, a lei 8.405 de 9 de janeiro de 1992, instituiu a reabertura da CAPES como fundação pública e subordinado ao MEC - Ministério da Educação e Cultura, sendo o seu principal objetivo o de manter o alto padrão do Sistema Nacional de Pós-Graduação brasileiro, bem como, induzir e fomentar a formação inicial e continuada de professores para a educação básica.

Este órgão também é responsável pela definição dos critérios de normatização que classificam as revistas acadêmicas. A cada triênio os periódicos são avaliados pela área de conhecimento correspondente e classificados conforme os critérios definidos pelo o web qualis periódicos, sendo que, A1, o mais elevado; A2; B1; B2; B3; B4; B5; C - com peso zero. Um pesquisador vinculado ao um programa de pós-graduação, ao publicar em um periódico A1 irá contar com 100 pontos, e em periódico B5 com 10 pontos. No quadro 1 é apresentado os critérios utilizados para inclusão dos periódicos em cada estrato. Esses foram retirados do documento de área denominado Administração, Ciências Contábeis e Turismo referente ao ano de 2012.

Quadro 1 - Atualização do webqualis da área Administração, Ciências Contábeis e Turismo

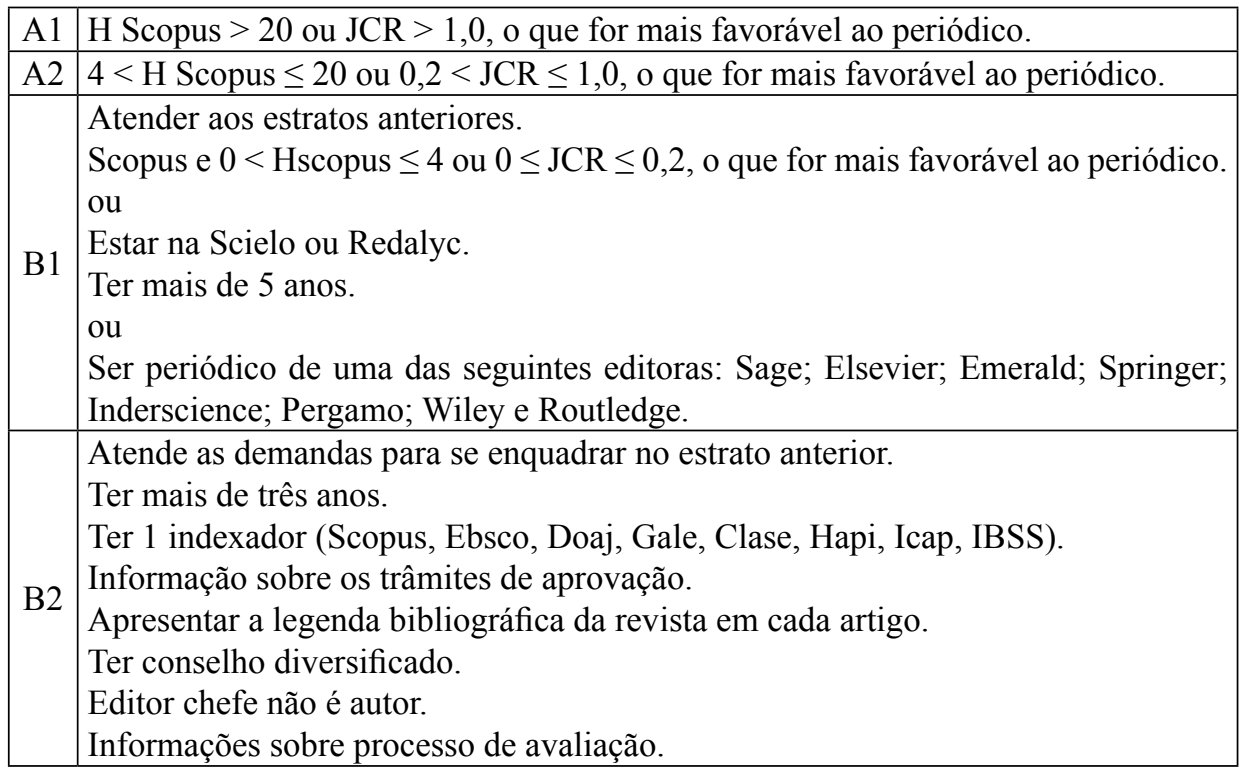




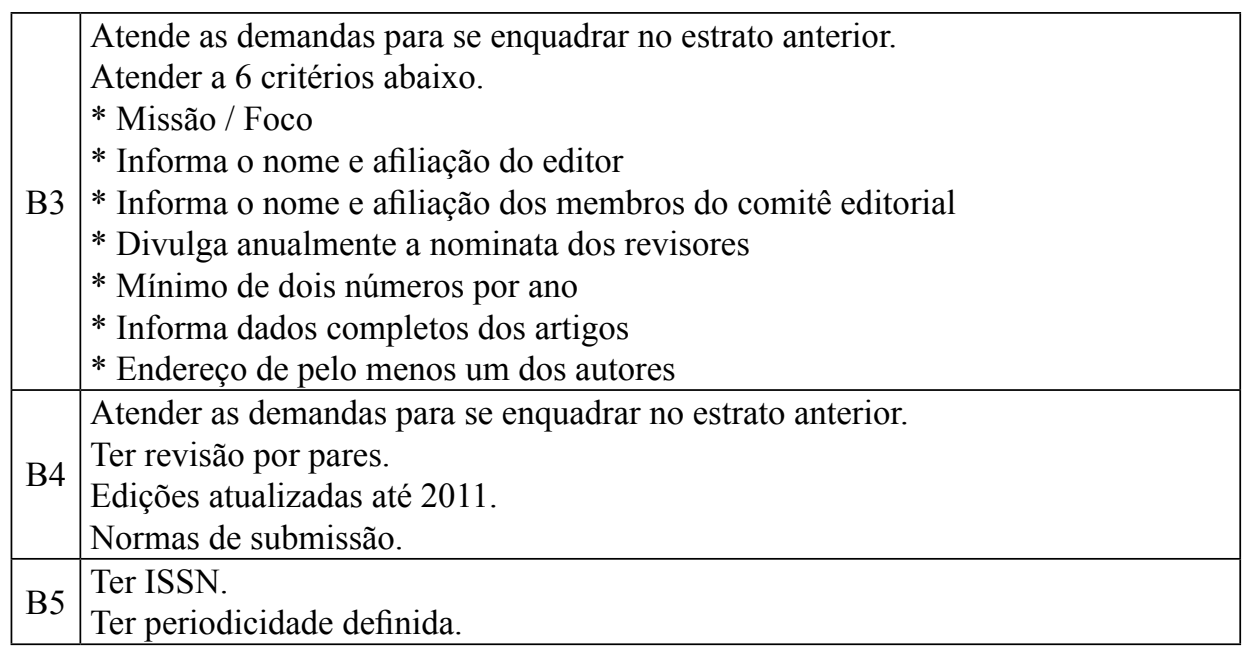

Fonte: Brasil (2012)

Gruszynski e Sanseverino (2005) destacam a importância do processo avaliativo no universo da editoração científica, dado que, a cada ano aumenta o número de títulos novos, a exemplo do que ocorre na área de Administração, em 2007 contava com 394 periódicos, em 2010 com 1503, em 2013 totaliza 1829 periódicos, ou seja, um aumento de mais de 300\%.

\subsubsection{Normatização}

Miranda e Pereira (1996), Gruszynski e Sanseverino (2005) e Sandes-Guimarães (2012), descrevem qual é a função do periódico científico junto a comunidade acadêmica, no entanto, Sabadini et al (2009) fornece as características ao que diz respeito ao formato e estrutura. Vale ressaltar que cada aspecto é considerado obrigatório, caso contrário, a categoria dada a revista como "científica" será comprometida.

Inicialmente Sabadini et al (2009) informa que as revista científicas assumem duas características distintas, extrínsecas e intrínsecas. A primeira está voltada para práticas editoriais explicitas descrita como, critérios e procedimentos para seleção e avaliação de artigos, política editorial clara, instruções aos autores, normalização, tempo de existência do periódico, regularidade de publicação, indexação em bases de dados nacional e internacional, tiragem e apresentação gráfica. A segunda característica denominada 
como intrínsecas, diz respeito ao corpo editorial, sistema de avaliação por pares e integração do autor com o leitor.

Com base nos critérios internos e externos, Sabadini et al (2009) informa quais os requisitos mínimos ${ }^{2}$ para o funcionamento de uma revista acadêmica, conforme apresentados no quadro 2:

Quadro 2 - Critérios para funcionamento de uma revista acadêmica

\begin{tabular}{|c|c|}
\hline Requisitos & Ação \\
\hline Normalização & $\begin{array}{l}\text { A revista deve informar a norma a qual as publicações submetidas } \\
\text { deverão obedecer. As normas existentes: } \\
\text { ABNT - Associação Brasileira de Normas Técnicas } \\
\text { APA - Publication Manual of the American Psychological Association } \\
\text { Vancouver - International Committee of Medical Editors - ICMJE }\end{array}$ \\
\hline Periodicidade & $\begin{array}{l}\text { A frequência das revistas pode ser: } \\
\text { diária, semanal, quinzenal ou bimensal, mensal, bimestral, trimestral, } \\
\text { semestral, anual, bienal e trienal }\end{array}$ \\
\hline Regularidade $^{*}$ & $\begin{array}{l}\text { A partir da escolha da periodicidade, a revista deve manter a regulari- } \\
\text { dade sem que haja atrasos. }\end{array}$ \\
\hline Missão & Deve estar disponível para toda a comunidade acadêmica. \\
\hline $\begin{array}{l}\text { Avaliação } \\
\text { pelos pares }\end{array}$ & Deve ser pelo processo blind review \\
\hline Expediente & $\begin{array}{l}\text { Deve apresentar informações como nome o completo e a afiliação de } \\
\text { todos os integrandos que pertencem ao corpo editorial. }\end{array}$ \\
\hline Indexadores & $\begin{array}{l}\text { A revista deve estar indexada em bases de dados que promovam } \\
\text { indicadores de qualidade, a exemplo do fator de impacto e também } \\
\text { visibilidade. }\end{array}$ \\
\hline ISSN & Número Internacional Padronizado para Publicações Seriadas \\
\hline
\end{tabular}

* Na área de Administração o Manual de Boas Práticas da Publicação Científica, recomenda a publicação de no minimo dois fascilos por ano.

Fonte: autora

Vale destacar que todo o processo normativo é fomentado pela CAPES (TRZESNIAK et al, 2012). Revistas bem normatizadas transmitem seriedade por meio de seu fluxo editorial à comunidade acadêmica, consequentemente, alcançando os melhores estratos no web qualis e atraindo os pesquisadores mais renomados da área de atuação.

\footnotetext{
2 Critérios extraídos também do Manual de Boas Práticas da Publicação Científica, elaborado pela ANPAD - Associação Nacional de Pós-Graduação e Pesquisa em Administração. Disponível em http://www.anpad.org.br/diversos/ boas_praticas.pdf
} 


\subsubsection{Indexação}

Para Santos (2010), "indexação é a operação que consiste em recuperar, selecionar e exprimir as informações contidas nos documentos. Trata-se de uma operação de descrição interna, cujo objetivo é o conteúdo intelectual dos documentos. Através dela, as informações selecionadas dos documentos são expressas por meio de termos de indexação pertencentes a uma ou várias linguagens documentais" (SANTOS, 2010, p. 5). Strehl (1998) acrescenta a esta definição que os serviços de indexação é uma forma de buscar qualquer tipo de documento ou informação em sistemas computacionais.

Para garantir a sobrevivência das revistas acadêmicas, é necessário indexá-las em bases de dados relevantes que possam garantir visibilidade e acessibilidade. Algumas áreas do conhecimento possuem bases especificas de indexação, é o caso da Medicina, o principal indexador é o PubMed. Contudo, além dos indexadores específicos da área de conhecimento, há dois indexadores multidisciplinares que para o meio acadêmico, se a revista está inserida em uma delas, significa dizer que o periódico esta associado a critérios de qualidade. Os indexadores ISI-Thompson e Scopus são os mais relevantes no cenário da editoração científica, em virtude de emitirem indicados bibliométricos (JCR - Journal Citations Reports e o H-Scopus - SCImago Journal \& Country Rank, respectivamente) que é um recurso que tem por fim, medir a produção científica dos autores, e, aferir a qualidade das publicações dos periódicos proporcionando, assim, um ranking de revistas acadêmicas.

Ao analisar o quadro 1 observa-se que, uma revista para obter os extratos mais elevados no web qualis, além conseguir a indexação nas referidas bases, uma vez que é exigido extremo rigor em relação a: qualidade editorial, normatização, texto, pontualidade, entre outros fatores, a revista deve necessariamente possuir os indicadores bibliométricos.

\section{ANÁLISE DOS RESULTADOS}

Face ao que foi apresentado, o que se observa no mercado editorial científico é uma clara intervenção governamental. Esta por sua vez, não sendo mediante aos bens públicos (pela definição, não há como categorizar 
os periódicos como bem publico) e igualmente com o monopólio natural, ao contrário, o mercado de periódicos científicos conforme mencionado anteriormente, apresenta um total de 1.829 na área de Administração, podendo-se afirmar que é um mercado competitivo.

Nesse contexto, a intervenção do poder público se da por meio de duas circunstâncias: assimetria de informação e a externalidade positiva.

Na primeira situação, ao mesmo tempo em que o pesquisador é um fornecedor, ele é também consumidor da revista. A comunidade acadêmica, principal consumidor da produção científica, necessita saber se os resultados de pesquisas que estão sendo apresentados tem validade científica. Neste caso, o pesquisador tem mais informação sobre a sua pesquisa do que o leitor. Deste modo, o governo intervém neste mercado criando mecanismos para incentivar a qualidade dos periódicos, e, atribuindo uma classificação para aqueles que cumpram os requisitos estabelecidos. Um periódico bem classificado no web qualis, é respeitado e visto com bons olhos por toda comunidade científica, além de atrair os melhores pesquisadores para publicação.

A CAPES ao premiar as revistas com extratos A1 e A2 àquelas que possuem os indicadores JRC ou H-Scopos, necessariamente está incentivando para que as revistas nacionais sejam conduzidas à internacionalização. A implementação de tal medida, pode ser vista também, como uma ação governamental para incentivar a visibilidade internacional da produção científica nacional. As revistas que apresentam os referidos indicadores, por se tratarem de bases de dados internacionais, a origem das citações podem ser de diversos países.

A internacionalização da produção científica é crucial, pois, possibilita o intercambio do conhecimento, o compartilhamento das similaridades e potencializa as diferenças, além de, aumentar a visibilidade.

Neste contexto, a externalidade é a segunda situação de intervenção do poder público. Este intervém na economia para incentivar o conhecimento científico, com a finalidade de que, os resultados produzidos pela ciência sejam revertidos para o bem estar da sociedade. Pinheiro, Silveira e Bazzo (2009) alegam que "o investimento na ciência e na tecnologia são como motores de progresso e proporcionam não só o desenvolvimento do saber humano, mas também uma evolução para o homem" (PINHEIRO, SILVEIRA, BAZZO, 2009, p. 1) 
O governo ao criar agências como o CNPq - Conselho Nacional de Desenvolvimento Científico e Tecnológico e as FAPs - Fundações Estaduais de Amparo à Pesquisa - agências destinadas a fomentar a trabalho científico, bem como, capacitar e qualificar o pesquisador, vai ao encontro do que os autores Pinheiro, Silveira e Bazzo (2009) chamam de "modelo linear" - desenvolvimento: + ciência $=+$ tecnologia $=+$ riqueza $=+$ bem-estar social.

Pode-se traçar um paralelo aos problemas que são gerados pela assimetria de informação, especificadamente seleção adversa e risco moral, e aplicá-los ao mercado editorial científico.

A seleção adversa vincula-se aos processos intrínsecos da revista, em especifico, ao processo de seleção e avaliação pelos pares.

Para garantir a qualidade do que será publicado, o fluxograma do processo editorial inicia-se com um desk review, neste analisa-se a adequação editorial, adequação da linguagem e o quanto o artigo contribui para a área de conhecimento. Aprovado nesta primeira etapa, o texto é encaminhado para avaliação double blind review, feitas por membros da revista capacitados à avaliarem a efetiva qualidade do artigo. Uma das regras de normatização da revista acadêmica é que ele publique uma quantidade mínima de artigos ao longo do ano, este número se diferencia para cada área de conhecimento. Entretanto, em virtude desta pressão, a revista não pode aceitar publicar artigos que sejam mosaicos, frutos de manuscritos sem qualquer cuidado formal ou científico.

O desk review e o processo de avaliação pelos pares são recursos estratégicos, que tem por fim, evitar a publicação de artigos aventureiros, de forma a evitar a exposição da revista a falta de credibilidade. Haja vista que, necessariamente, só sobrevivem aquelas que transmitem confiança e boa reputação no meio acadêmico.

No âmbito da editoração científica o risco moral ocorre quando surgem indícios de plágio ou fraude na pesquisa após a sua publicação. Por este motivo, os indexadores cada vez mais exigem dos periódicos a adoção de códigos de éticas e conduta, ou, a associação a institutos como COPE - Committee on Publication Ethis, que em casos de malversação, garantem o fornecimento de procedimentos cabíveis para lidar com a situação. A exemplo do que ocorre com o indexador Scopos, se a revista 
não disponibilizar um código de ética aos usuários, não pode solicitar o processo de avaliação junto a base.

Resumindo, a seleção adversa são os cuidados que a revista deve ter antes de publicar o artigo, e o risco moral, indícios de fraude após a publicação. A revista não tem acesso à informação em todos os aspectos da pesquisa.

A sinalização de mercado no contexto editorial pode ser caracterizada pela busca de diferenciação entre as diversas revistas existentes. A possibilidade de diferenciação é possível somente quando essas estão indexadas em bases de dados relevantes. Para Trzesniak (2012) os indexadores têm como proposito "oferecer visibilidade aos trabalhos e de auxiliar pesquisadores a se manterem atualizados em suas áreas de interesse" Ainda o mesmo autor alega que, o fato de várias revistas demandarem indexação, fez com que essas bases praticassem a seleção de publicação, fato que levou o mercado a criar "casta de revistas indexadas" as quais são extremamente valorizadas e vistas com aura de prestígio. (TRZESNIAK, 2012, p. 60).

Os indexadores localizados no hemisfério norte, citados anteriormente, têm perfis comerciais, acesso fechado, porém, são os mais requisitados, devido a sua tradição e tempo de atuação. Os do hemisfério sul, como por exemplo, Redalyc e Scielo, não são tradicionais como o primeiro, no entanto, cada vez mais ganham relevância no cenário científico, pois além de priorizar o acesso aberto, contam com critérios de admissão claros e transparentes. Tanto os indexadores do hemisfério norte quanto os do sul, contribuem com a questão de seletividade da revista.

\section{CONCLUSÃO}

A base SJR - SCImago Journal \& Country Rank possibilita gratuitamente a consulta de diversos indicadores, entre eles, H-Index, ranking dos journals e países, entre outros. Ao contrário do JCR que para acessá-lo, é necessária assinatura.

Ao examinar o ranking em termos de produtividade dos dez primeiros países, encontraremos a seguinte situação descrita no quadro 3: 
Quadro 3 - Ranking por país com base na Produtividade.

\begin{tabular}{|c|c|}
\hline Posição & Países \\
\hline 1a. & Estados Unidos \\
\hline 2a. & China \\
\hline 3a. & Reino Unido \\
\hline 4a. & Alemanha \\
\hline 5a. & Japão \\
\hline 6a. & França \\
\hline 7a. & Canadá \\
\hline 8a. & Itália \\
\hline 9a. & Espanha \\
\hline 10a. & Índia \\
\hline
\end{tabular}

Fonte: SJR - SCImago Journal \& Country Rank

Ao observarmos o quadro 3, constata-se que, entre os dez países mais produtivos cientificamente, percebe-se a presença dos países denominados como G7 (formado pelos sete países mais ricos ou industrializado), entre eles: Estados Unidos, Canadá, Japão, Alemanha, Inglaterra, França e Itália. Não é surpresa encontrar no ranking dois países que pertencem ao BRICs, (sigla que se refere a Brasil, Rússia, Índia, China e África do Sul, que se destacaram no cenário mundial pelo rápido crescimento das suas economias em desenvolvimento). O Brasil sendo parte do segundo grupo de países configura a $15^{\mathrm{a}}$. posição.

Se análise for pelo o índice bibliométrico, no caso o H-index, notase que os países do G7 também assumem posição de liderança entre os países que têm mais citações na literatura científica, conforme apresentado no quadro 4. 
Quadro 4 - Ranking por país com base no índice de citação H-Index.

\begin{tabular}{|c|c|}
\hline Posição & Países \\
\hline 1a. & Estados Unidos \\
\hline 2a. & Reino Unido \\
\hline 3a. & Alemanha \\
\hline 4a. & França \\
\hline 5a. & Canadá \\
\hline 6a. & Japão \\
\hline 7a. & Itália \\
\hline 8a. & Holanda \\
\hline 9a. & Suíça \\
\hline 10a. & Austrália \\
\hline
\end{tabular}

Fonte: SJR - SCImago Journal \& Country Rank

Os países dos BRICs pela análise do H-index, configuram posições bem diferentes, o que significa dizer que, entre os países em desenvolvimento há indícios que a produção científica esteja em crescimento, contudo, não há qualidade e nem visibilidade. No quadro 5 é apresentado a posição dos países no BRICs no ranking de citação.

Quadro 5 - Ranking dos BRICs com base no índice de citação H-Index

\begin{tabular}{|c|c|}
\hline Posição & Países \\
\hline $16^{\mathrm{a}}$. & China \\
\hline $21^{\mathrm{a}}$. & Rússia \\
\hline $22^{\mathrm{a}}$. & Brasil \\
\hline $24^{\mathrm{a}}$. & Índia \\
\hline $35^{\mathrm{a}}$. & África do Sul \\
\hline
\end{tabular}

Fonte: SJR - SCImago Journal \& Country Rank 
A presença dos países pertencentes ao G7 nos rankings de produtividade, bem como, no índice de citação, leva a inferir que o desenvolvimento científico está associado ao desenvolvimento econômico. É claro que esta reflexão pauta-se somente nos dados que foram levantados. É necessário estudos positivitas sofisticados para identificar se existe correlação no que esta sendo proposto. Também não foram levantadas evidencias se o desenvolvimento científico desses países é uma consequência da intervenção do estado ou da iniciativa privada.

No que diz respeito ao Brasil, a interferência do Estado vem produzindo resultados positivos. Conforme apresentado na introdução deste trabalho, o país saiu da $17^{\mathrm{a}}$. e alcançou a $13^{\mathrm{a}}$. posição mundial na produção de artigos científicos. Parte deste crescimento deve-se em parte a política conduzida pela CAPES aos cursos de pós graduação Stricto Sensu, que incentiva a produção científica. Conforme apresentado nos quadros 3 e 4, a produção científica nacional apesar da alta produtividade, tem pouca visibilidade internacional e qualidade. Os periódicos científicos necessitam criar estratégias, sejam elas, publicar artigos em inglês, parcerias em eventos internacionais, publicar com pesquisadores de outras nacionalidades, atrair pesquisadores internacionais, entre outras ações, para que o impacto na produção nacional seja viabilizado.

\title{
SCIENTIFIC PUBLISHING IN THE LIGHT OF ECONOMIC CONCEPTS
}

\begin{abstract}
:
This paper aims to analyze the existence of the scientific publishing market and its need for internationalization in light of economic concepts, having in view settings as information asymmetry and market failures. The conclusion of this study is that government intervention leads to scientific productivity, however, does not lead to internationalization.

Keywords: scientific production; government intervention; Internationalization; Economy
\end{abstract}

JEL Classification: O2; O29 


\section{REFERÊNCIAS}

ANDERSON, W. L. "Falhas de mercado" e informações assimétricas. Instituto Ludwig von Mises - Brasil [Portal]. Disponível em: < http://www. mises.org.br/About.aspx>. Acesso em: 17/01/14.

ALISSON, E. Revistas científicas brasileiras ainda têm baixo impacto internacional. Agência FAPESP [Portal]. Disponível em: <http://agencia. fapesp.br/16332>. Acesso em: 26/12/2013.

ALISSON, E. Revistas científicas de países emergentes aumentam processo de internacionalização. Agência FAPESP [Portal]. Disponível em: < http:// agencia.fapesp.br/18142>. Acesso em: 27/12/2013

BRASIL. Ministério da Educação. Coordenação de Aperfeiçoamento de Pessoal de Nível Superior. Diretoria de Avaliação. Comunicado no. 002/12 - Área de Administração, Ciências Contábeis e Turismo. Atualização do Webqualis da área. 2012.

BRASIL. Ministério da Educação. Coordenação de Aperfeiçoamento de Pessoal de Nível Superior. [Portal]. Disponível em: < http://www.capes. gov.br/>. Acesso em: 17/01/13.

CAMPOS, H. A. Falhas de mercado e falhas de governo: uma revisão da literatura sobre regulação econômica. Prismas: Dir., Pol. Publ. e Mundial, Brasília, v. 5, n. 2, p. 341-370, jul. / dez. 2008.

CARVALHO, N. et al. Efeitos da assimetria de informação sobre os custos de transação da cadeia produtiva da batata. In: VII Simpósio de Excelência em Gestão e Tecnologia, 2010, Espírito Santo, Anais... Espírito Santo: SEGeT, 2010. p. 15.

COSTA, N. R. et. al. O desenho institucional da reforma regulatória e as falhas de mercado no setor saúde. RAP-Revista de Administração Pública, Rio de Janeiro, v. 35, n. 2, p. 193-228, mar. / abr. 2001. 
FIORIN, J. L. Internacionalização da produção científica: a publicação de trabalhos de Ciências Humanas e Sociais em periódicos internacionais. Revista Brasileira de Pós Graduação, Brasília, v. 4, n. 8, p. 263-281, dez. 2007.

GRUSZYNSKI, A. C.; SANSEVERINO, A. M. V. O periódico científico na área de Humanidades: critérios de avaliação. In: XXVIII Congresso Brasileiro de Ciências da Comunicação, 2005, Rio de Janeiro. Anais... Rio de Janeiro: Intercom, 2005.

LIMA, C. R. M. Informação, assimetria de informações e regulação do mercado de saúde suplementar. Enc. Bibli: R. Eletr. Bibliotecon. Ci. Inf., Florianópolis, no. esp., $1^{\text {o }}$. sem. 2006.

MANSFIELD, E.; YOHE, G. Microeconomia. São Paulo: Saraiva, 2006. $640 \mathrm{p}$.

MIRANDA, D. B.; PEREIRA, M. N. F. O periódico científico como veículo de comunicação: uma revisão da literatura. Ciência da Informação, Brasília, v. 25, n. 3, p. 375-382, set. / dez. 1996.

PACKER, A. L. Os periódicos brasileiros e a comunicação da pesquisa nacional. Revista USP, São Paulo, no. 89, p. 26-61, mar/mai 2011.

OMAR, J. H. D. O papel do governo na economia. Indicadores Econômicos FEE, Porto Alegre, v. 29, n. 1, p. 211-235, 2001.

PINDYCK, R. S.; RUBINFELD, D. L. Microeconomia. São Paulo: Pearson, 2004. $711 \mathrm{p}$.

PINHEIRO, N. A. M.; SILVEIRA, R. M. C. F., BAZZO, W. A. O contexto científico-tecnológico e social acerca de uma abordagem crítico-reflexiva: perspectiva e enfoque. Revista Iberoamericana de Educación, no. 49, marzo / 2009.

REGALADO, A. Brazilian Science: Riding a Gusher. Science, vol. 330, no. 6009, pp. 1306-1312, December 2010. DOI: 10.1126/science.330.6009.1306. 
Disponível em: < http://www.sciencemag.org/content/330/6009/1306. summary $>$. Acesso em: 01/11/2013.

REIS, V. M. S. Ensaios sobre seleção adversa e risco moral no mercado de crédito. 2012. 86 f. Dissertação (Mestrado em Economia da Informação) - Escola de Economia de São Paulo da Fundação Getúlio Vargas, São Paulo. 2012.

SABADINI, A. A. Z. P. et al. Preparando um Periódico Científico. In SABATADINI, A. A. Z. P. et al (Org): Publicar em psicologia. Um enfoque para a revista científica. São Paulo, Casa do Psicólogo, p. 35-74.

SANDES-GUIMARÃES, L. V. Gestão de periódicos científicos: um estudo com revistas da área de administração. 2013. 134 f. Dissertação (Mestrado em Administração Pública e Governo) - Fundação Getúlio Vargas, São Paulo. 2013.

SANDES-GUIMARÃES, L. V.; DINIZ, E. H. Análise do modelo de gestão de periódicos científicos da área de Administração. In: XXXVII Encontro da ANPAD, 2013, Rio de Janeiro. Anais...Rio de Janeiro: EnANPAD, 2013.p. 1-16.

SANTOS, G. C. Fontes de indexação para periódicos científicos. Um guia para bibliotecários e editores. UNICAMP - Faculdade de Educação - Biblioteca. Série: Manuais Técnicos BFE - no. 5. Campinas. 2010.

SCImago. SJR — SCImago Journal \& Country Rank. http:/www.scimagojr. com. Acesso em: 17/01/2014.

SCHETTINO, T. S. Inclusão social e "assimetria de informação" no sistema de ensino superior brasileiro. 2006. 146 f. Dissertação (Mestrado em Sociologia e Antropologia) - Universidade Federal do Rio de Janeiro, Rio de Janeiro. 2006.

SEABRA, L. O que é risco moral? Economia Clara [Portal]. Disponível em: $<$ http://economiaclara.wordpress.com/2009/11/30/o-que-e-risco-moral/> Acesso em: 17/01/13. 
SOTO, J. H. As definições corretas de monopólio e concorrência - e por que a concorrência perfeita é ilógica. Instituto Ludwig von Mises - Brasil [Portal]. Disponível em: < http://www.mises.org.br/About.aspx > . Acesso em: 17/01/14.

STREHL, L. O Fator de impacto do ISI e a avaliação da produção científica: aspectos conceituais e metodológicos. Revista Ciência da Informação, Brasília, v. 34, n.1, p. 19-27, jan./abr. 2005.

TRZESNIAK, P. et al. Qualidade de Conteúdo, o Grande Desafio para os Editores Científicos. Revista Colombiana de Psicologia, Bogotá, v. 21, n. 1, p. 57-75, enero/junio 2012.

VARIAN, H. R. Microeconomia princípios básicos. Rio de Janeiro: Editora Campus, 1999. 740 p. 